\title{
Avaliação do perfil metabólico e proteína $C$ reativa em cães obesos
}

\author{
Marcelle Mareze $^{1 *}$, Letícia Misturini Dalla Costa ${ }^{2}$, Priscila Michelin Groff ${ }^{3}$, Joselaine \\ Bortolanza Padilha $^{3}$, Fernanda Pinto Ferreira ${ }^{1}$, Juliana Mareze ${ }^{1}$, Itacir Eloi Sandini ${ }^{4}$ \\ Margarete Kimie Falbo 5
}

\footnotetext{
${ }^{1}$ Mestranda em Ciência Animal - Universidade Estadual de Londrina, Departamento de Medicina Veterinária Preventiva. Londrina, Paraná, Brasil.E-mail: marcelle_mareze@hotmail.com,nandaferreiravet@gmail.com, juliana_mareze@hotmail.com ${ }^{2}$ Médica Veterinária - Francisco Beltrão, Paraná, Brasil. E-mail le_mdc@hotmail.com

${ }^{3}$ Mestranda em Zootecnia - Universidade Tecnológica da Federal do Paraná, Dois Vizinhos, Paraná, Brasil. E-mail: priscilagroff@hotmail.com

${ }^{4}$ Professor Doutor - Universidade Estadual do Centro-Oeste, Departamento de Agronomia. Guarapuava. Paraná, Brasil

${ }_{5}^{5}$ Professora Doutora - Universidade Estadual do Centro-Oeste, Departamento de Medicina Veterinária. Guarapuava-Paraná, Brasil. Email: fabiana.santos@ifgoiano.edu.br

*Autor para correspondência
}

\begin{abstract}
RESUMO. A domesticação dos animais, fez com que a mudanças no hábito e manejo alimentar desenvolvessem diferentes respostas metabólicas. A obesidade é uma doença nutricional multifatorial, que aumenta o risco de várias complicações na saúde do animal. Em humanos, a proteína $\mathrm{C}$ reativa vem sendo estudada para complementar o diagnóstico de obesidade, já que a prevalência desta doença é crescente. Este trabalho teve como objetivo verificar possíveis alterações nos exames laboratoriais de hemograma, perfil bioquímico metabólico e avaliar o comportamento da proteína $\mathrm{C}$ reativa em cães obesos. Foram comparados doze cães obesos, classificados com escore de condição corporal (ECC) 9,0 e doze cães, grupo controle, com ECC 5, de uma escala que varia de 1 a 9 , ambos grupos eram aparentemente saudáveis, de ambos os sexo e de raças variadas. Através dos estudos, pode-se observar que não houve alterações no hemograma e nos níveis da proteína $\mathrm{C}$ reativa de todos os animais. Quando comparados às dosagens séricas bioquímicas de ambos os grupos, não verificou-se alterações, com exceção dos níveis séricos de colesterol total e triglicerídeos, que comportaram-se diferentemente entre os dois grupos de acordo com as análises estatísticas. Apenas a dosagem dos triglicerídeos do grupo obeso, apresentou-se elevado nos níveis séricos. Através dos dados epidemiológicos, houve diferença estatística significativa $(p=0,01)$ entre o ECC e a castração dos animais, esses fatores sugerem uma predisposição à obesidade. Pode-se concluir que a proteína $\mathrm{C}$ reativa em cães tem comportamento diferente do encontrado nos humanos.
\end{abstract}

Palavras chaves: cães, colesterol, obesidade, triglicerídeos

\section{The metabolic profile assessment and C-reactive protein in obese dogs}

\begin{abstract}
Domestication of animals, changes in habit and feed management has an important role in metabolic response of these animals. Obesity is a multi factorial nutrition disorder, which increases the risk of metabolic complications. The C-reactive protein has been considering important to diagnosing obesity in human, since its prevalence increases. This study aimed to verify the hematological and biochemical parameters and evaluate the behavior of C-reactive protein in obese dogs. Twelve obese dogs were compared and classified with body condition score (BCS) 9.0 and twelve from control group classified with ECC 5, scale ranging from 1 to 9, both groups were apparently healthy, of both sex and of varied breeds. No changes were observed in hematological and biochemical parameters and levels of C-reactive protein. In exception of serum total cholesterol and triglycerides, which behaved differently between both
\end{abstract}


groups according to statistical analysis. Levels of triglycerides from obese group showed high in serum. Using epidemiological data, there was a statistically significant difference $(\mathrm{p}=0.01)$ between the ECC and castrates animals, these factors suggest a predisposition to obesity. It can be concluded that C-reactive protein in dogs have different behavior from that found in humans.

Key words: cholesterol, dogs, obesity, triglycerides

\section{Introdução}

O manejo alimentar dos animais de estimação sofreu algumas modificações no decorrer dos anos, sendo a domesticação e o consequente estreitamento na relação homem e animal importante causa desta mudança. A inclusão de alimentos de alta densidade energética, aumento no número de refeições, a quantidade fornecida, uso de petiscos e sobras, são fatores relacionados ao aumento de peso (German, 2006).

Embora a obesidade seja considerada uma doença essencialmente nutricional, outros fatores podem predispô-la, como a genética e o sedentarismo. $\mathrm{O}$ sobrepeso é considerado prejudicial à saúde, pois favorece o aparecimento de outras doenças, dentre elas, as ortopédicas, cardiopulmonares, dermatológicas, endocrinopatias e reprodutivas e neoplásicas, além de um maior risco de complicações anestésicas em animais que apresentam dislipidemia (German, 2006).

A obesidade está relacionada com o aumento das células do tecido adiposo, produtoras de fatores inflamatórios como interleucina-6, fator de necrose tumoral- $\alpha$, que causam inflamação persistente, de baixo grau, secundária a obesidade, que, juntamente com o aumento do estresse oxidativo contribuem para o aparecimento das doenças relacionadas a essa condição (Laflamme, 2006).

A proteína $\mathrm{C}$ reativa $(\mathrm{PCR})$ é produzida no fígado, em respostas ao estímulo de citocinas inflamatórias, e é considerado um biomarcador preciso da inflamação. Em humanos, desde a década de 1970, sua dosagem é utilizada para diagnóstico de processos inflamatórios e infecções. Estudos comprovam que existe relação no aumento dos níveis desta proteína na obesidade (Park et al., 2005, Brasil et al., 2007).

O objetivo deste trabalho foi avaliar o perfil metabólico em cães obesos e investigar se o comportamento da proteína $\mathrm{C}$ reativa é semelhante ao descrito em humanos.

\section{Material e Métodos}

O presente estudo foi realizado com aprovação do Comitê de Ética da Universidade Estadual do Centro-Oeste, em Guarapuava - PR, Campus CEDETEG, sob registro $\mathrm{n}^{\circ}$ 014/2012, consentimento e esclarecimento do proprietário.

Durante o estudo foram analisados 24 cães, divididos em dois grupos. $\mathrm{O}$ diagnóstico para a obesidade em cães foi realizado pela palpação corporal de acordo com a tabela sugerida por Laflamme (1997) com o escore de condição corporal (ECC) variando de 1 a 9. Os cães selecionados estavam entre o ECC8 a 9 (obesos) e ECC 5 (controle), ambos os grupos eram formados por sete fêmeas e cinco machos. Estes animais foram selecionados de acordo com o ECC; porém aleatoriamente, com indistinção de sexo, raça ou tamanho, variando de médio a grande porte.

A coleta de sangue foi realizada por punção da veia cefálica em cães com jejum mínimo de oito horas. As amostras foram distribuídas em tubos de ensaios estéreis sem e com anticoagulante (EDTA), e encaminhadas em caixa isotérmica ao Laboratório de Patologia Clínica Veterinária da UNICENTRO, no qual foi realizado hemograma completo com o sangue total. O tubo sem anticoagulante foi centrifugado e após a retração do coágulo, o soro foi acondicionado em microtubos de polietileno e mantido a $-20^{\circ} \mathrm{C}$ até o processamento da amostra. Os parâmetros analisados foram: glicose, colesterol total, triglicerídeo, alanina amino transferase (ALT), fosfatase alcalina (FA), determinados por colorimetria em analisador bioquímico semi-automático (BIOPLUS $200^{\circledR}$ ) e proteína C-reativa, através da utilização de partículas de látex revestidas com anticorpo monoclonal anti-PCR por aglutinação direta. As amostras foram analisadas com kits comerciais Labtest ${ }^{\circledR}$, e os resultados tabulados e analisados pelo Teste de Tukey a 5\% de probabilidade, com o programa de análises estatísticas SISVAR (Ferreira, 2011). 
Foi aplicado um questionário com perguntas referentes à idade, sexo, tipo de alimentação, manejo, ambiente, status reprodutivo, entre outras questões. A aplicação deste foi realizada diretamente com os responsáveis e seus cães de estimação. As análises estatísticas dos destes epidemiológicos foram avaliadas no programa Epiinfo 3.5.4 (Dean et al., 1990), pelo teste de Qui quadrado corrigido por Yates, considerandose o nível de significância de $5 \%$.

\section{Resultados e Discussão}

De acordo com Murata et al. (2004) as proteínas de fase aguda são um grupo de proteínas que agem de uma forma independente de anticorpos, contribuem para restaurar a homeostase e limitar o crescimento microbiano nos animais, como a infecção, inflamação, trauma cirúrgico ou estresse. A concentração destas proteínas na circulação está relacionada com a gravidade da doença e extensão do dano tecidual e sua quantificação pode fornecer informações de diagnóstico e de prognóstico. Neste contexto, estudos com pessoas obesas descrevem um aumento nos níveis séricos da proteína C reativa (Park et al., 2005), em cães obesos há poucos estudos. Os resultados obtidos no nosso trabalho para proteína $\mathrm{C}$ reativa tanto para os cães normais quanto para os cães obesos foram negativos.

As fêmeas castradas têm maior predisposição ao ganho excessivo de peso quando comparados aos machos castrados. A predisposição sexual está relacionada com a diminuição na concentração de hormônios andrógenos e da menor taxa metabólica em fêmeas (McGreevy et al., 2005, German, 2006). Entre todos os animais analisados, 66,6\% (8/12) com ECC entre 8 e 9 (obesos), e 8,4\% (1/12) com ECC 5 (controle) eram castrados (Tabela 1), entre essas variáveis houve diferença estatística significativa $(\mathrm{p}=0,01)$, de acordo com a análise realizada no programa Epiinfo. Os dados sugerem que a castração pode ser um fator de predisposição à obesidade. Quanto ao tipo de alimentação, 58,3\% (7/12) dos obesos recebiam ração mais alimentação caseira ou petiscos como fonte de energia e 58,3\% (7/12) recebia somente ração como alimento, porém não houve diferença estatística significativa entre as duas variáveis.

Tabela 1. Comparação entre fêmeas e os machos castrados em relação à classificação do escore de condição corporal, Laboratório de Patologia Clínica da Universidade Estadual do Centro-oeste, Guarapuava - Pr, 2013.

\begin{tabular}{lccc}
\hline Sexos & Número de animais & Castrados & Não castrado \\
\hline Fêmeas ECC 8 a 9 & $7(100 \%)$ & $5(71,4 \%)$ & $2(28,5 \%)$ \\
Fêmeas ECC 5 & $7(100 \%)$ & $1(14,2 \%)$ & $6(85,7 \%)$ \\
\hline Machos ECC 8 a 9 & $5(100 \%)$ & $3(60 \%)$ & $2(40 \%)$ \\
Machos ECC 5 & $5(100 \%)$ & $0(0 \%)$ & $5(100 \%)$ \\
\hline
\end{tabular}

ECC - Escore de condição corporal. ECC 8 a 9 - obesos, ECC 5 - normais.

Comparando as médias das variáveis hematológicas, para avaliar a saúde dos cães, tanto os animais do grupo controle como do grupo obeso, permaneceram dentro da normalidade. A única alteração notada foi o aumento no nível de proteína total plasmática (PTP) dos cães obesos, que, pode ser explicado por Brunettoet al. (2011), que caracteriza a obesidade como estado inflamatório, este poderia proporcionar um leve aumento na produção de globulinas, aumentando assim os níveis de proteína total no sangue.

As médias das variáveis bioquímicas avaliadas no experimento estão expostas na tabela 2.
Os exames bioquímicos séricos avaliam as funções dos órgãos vitais do organismo, neste estudo foram analisadas as dosagens séricas que determinam as funções metabólicas, entre elas glicose, alanina amino transferase (ALT), fosfatase alcalina (FA), colesterol e triglicerídeos (Hoffmann and Solter, 2008). Essas análises foram escolhidas para descartar a possibilidade de outras doenças que poderiam levar a alterações nos tais parâmetros.

As dosagens de glicose, ALT, FA e colesterol total dos dois grupos estavam dentro dos valores de referência, no entanto, todos os parâmetros séricos analisados do grupo obeso apresentaramse mais elevados quando comparados ao grupo controle. 
Tabela 2. Média das variáveis bioquímicas séricas, comparando os cães normais e os cães obesos, Laboratório de Patologia Clínica da Universidade Estadual do Centro-oeste, Guarapuava - Pr, 2013.

\begin{tabular}{lccccc}
\hline Cães & Glicose & ALT & FA & Colesterol & Triglicerídeos \\
& $\mathrm{mg} / \mathrm{dL}$ & $\mathrm{UI} / \mathrm{L}$ & $\mathrm{UI} / \mathrm{L}$ & $\mathrm{mg} / \mathrm{dL}$ & $\mathrm{mg} / \mathrm{dL}$ \\
\hline Normais & $86,0 \mathrm{a}$ & $50,4 \mathrm{a}$ & $74,1 \mathrm{a}$ & $155,6 \mathrm{~b}$ & $50,0 \mathrm{~b}$ \\
Obesos & $87,5 \mathrm{a}$ & $53,6 \mathrm{a}$ & $90,7 \mathrm{a}$ & $244,2 \mathrm{a}$ & $132,7 \mathrm{a}$ \\
Média & 86,8 & 52 & 82,45 & 199,8 & 91,41 \\
V.R. & $70-110^{*}$ & $21-86^{*}$ & $20-156^{*}$ & $135-270^{*}$ & $20-112^{*}$ \\
\hline
\end{tabular}

Médias seguidas pela mesma letra não diferem entre si pelo Teste de Tukey a 5\% de probabilidade. ALTAlanino amino transferase, FA- Fosfatase alcalina. Valores de referência segundo Kaneko et al. (2008).

Ao analisar o colesterol total $\mathrm{e}$ os triglicerídeos dos cães obesos, os valores foram superiores e apresentaram diferença estatística significante entre o grupo controle. Os níveis de triglicerídeos dosados no grupo obeso ultrapassaram os valore de referência. De acordo com Xenoulis and Steiner (2010) distúrbios endócrinos, pancreatite, colestase, obesidade e dietas ricas em gorduras são as causas mais comuns de hiperlipidemia secundária, pois a primária é rara e restrita a algumas raças.

A obesidade, a genética, a inflamação e os medicamentos, estão entre as principais causas desencadeadoras da diabetes mellitus (Nelson and Couto, 2015). Neste trabalho pode-se observar que nenhum animal de ambos os grupos apresentou hiperglicemia após o jejum.

A dosagem das enzimas hepáticas como a alanina aminotransferase (ALT) é utilizada como forma de diagnóstico de lesão hepática em cães, tais como degeneração e necrose hepatocelular, congestão e esteatose hepática (Kaneko et al., 2008). A fosfatase alcalina encontra-se aumentada na maioria dos casos de hiper adrenocorticismo e pela produção hepática de uma iso-enzima, induzida por altos níveis séricos de cortisol (Teske et al., 1989). Neste estudo não foi encontrado alterações na dosagem destas enzimas.

Em humanos a obesidade é um dos fatores desencadeantes da síndrome metabólica, caracterizada pela hipertensão, dislipidemia, obesidade e pela resistência à insulina. Clinicamente essa síndrome é alcançada quando pelo menos três desses fatores estão presentes (Zimmet et al., 2001). A relação entre a obesidade e a hipertensão em cães é controversa e de pouca importância clínica (Brown et al.,
2007). Embora os animais obesos não tenham apresentado hiperglicemia após o jejum e a pressão arterial não tenha sido mensurada, $58,3 \%$, a maioria deles apresentou níveis séricos de triglicerídeos próximos aos valores máximos aceitáveis dentro da normalidade ou ultrapassaram os valores de referência, o que os tornam grandes candidatos ao desenvolvimento desta síndrome.

\section{Conclusão}

Diferentemente dos humanos, a proteína $\mathrm{C}$ reativa não é um componente significativo para obesidade em cães. A avaliação do hemograma completo dos animais indicou a saúde dos animais, pois não apresentaram nenhuma alteração em ambos os grupos. Nas análises do perfil bioquímico sérico dos cães obesos (glicose, ALT, FA e colesterol total), apresentaram as maiores médias, porém dentro dos valores de referência, somente, a média dos triglicerídeo do grupo obeso ultrapassou os valores de referências. $\mathrm{O}$ colesterol total e os triglicerídeos foram os únicos parâmetros que exibiram diferença estatística significativa entre os grupos. Esses fatores indicam a possibilidade do desenvolvimento de doenças decorrentes ao elevado ECC. A castração é importante, porém pode pré-dispor a obesidade canina.

\section{Referências Bibliográficas}

Brasil, A. R., Norton, R. C., Rossetti, M. B., Leão, E. \& Mendes, R. P. (2007). C-Reactive protein as an indicator of low intensity inflammation in children and adolescents with or without obesity. Jornal de Pediatria, 83, 477-480. 
Brown, S., Atkins, C., Bagley, R., Carr, A., Cowgill, L., Davidson, M., Egner, B., Elliott, J., Henik, R. \& Labato, M. (2007). ACVIM Consensus Statement. Journal of Veterinary Internal Medicine, 21, 542-558.

Brunetto, M. A., Nogueira, S., Sá, F. C., Peixoto, M., Vasconcellos, R. S., Ferraudo, A. J., \& Carciofi, A. C. (2011). Correspondência entre obesidade e hiperlipidemia em cães. Ciência Rural, 41, 266-271.

Dean, A. G., Dean, J. A., Burton, A. H. \& Dicker, R. C. (1990). Epi Info: a generalpurpose microcomputer program for public health information systems. American Journal of Preventive Medicine, 7, 178-182.

Ferreira, D. F. (2011). SISVAR: A Computer Statistical Analysis System. Ciência $e$ Agrotecnologia, 35, 1039-1042.

German, A. J. (2006). The growing problem of obesity in dogs and cats. The Journal of Nutrition, 136, 1940S-1946S.

Hoffmann, W. E. \& Solter, P. F. (2008). Diagnostic enzymology of domestic animals. Clinical Biochemistry of Domestic Animals, 12, 351-378.

Kaneko, J. J., Harvey, J. W. \& Bruss, M. L. (2008). Clinical biochemistry of domestic animals. Academic press, New York.

Laflamme, D. P. (2006). Understanding and managing obesity in dogs and cats. Veterinary Clinics of North America: Small Animal Practice, 36, 1283-1295.

Laflamme, D. R. P. C. (1997). Development and validation of a body condition score system for dogs. Canine Practice, 22, 10-15.

McGreevy, P. D., Thomson, P. C., Pride, C., Fawcett, A., Grassi, T. \& Jones, B. (2005). Prevalence of obesity in dogs examined by Australian veterinary practices and the risk factors involved. Veterinary Record-English Edition, 156, 695-701.

Murata, H., Shimada, N. \& Yoshioka, M. (2004). Current research on acute phase proteins in veterinary diagnosis: an overview. The Veterinary Journal, 168, 28-40.

Nelson, R. W. \& Couto, C. G. (2015). Medicina interna de pequenos animais. Elsivier Editora, Amsterdan.

Park, H. S., Park, J. Y. \& Yu, R. (2005). Relationship of obesity and visceral adiposity with serum concentrations of CRP, TNF- $\alpha$ and IL-6. Diabetes Research and Clinical Practice, 69, 29-35.

Teske, E., Rothuizen, J., De Bruijne, J. J. \& Rijnberk, A. (1989). Corticosteroid-induced alkaline phosphatase isoenzyme in the diagnosis of canine hypercorticism. The Veterinary Record, 125, 12-14.

Xenoulis, P. G. \& Steiner, J. M. (2010). Lipid metabolism and hyperlipidemia in dogs. The Veterinary Journal, 183, 12-21.

Zimmet, P., Alberti, K. G. M. \& Shaw, J. (2001). Global and societal implications of the diabetes epidemic. Nature, 414, 782-787.

\section{Article History}

Received 27 June 2016

Accepted 13 July 2016

Available on line 12 August 2016

License information: This is an open-access article distributed under the terms of the Creative Commons Attribution License, which permits unrestricted use, distribution, and reproduction in any medium, provided the original work is properly cited. 